\title{
Sero-prevalence of RBC alloantibodies among Han and minority patients in Xinjiang
}

\author{
Xiaochuan Song ${ }^{*}$, Bin Liu, Yujiao Li, Min Ju, Jie Xu \\ Department of Transfusion Medicine, the First Affiliated Hospital of Xinjiang Medical University, Urumqi, Xinjiang, 830011, China
}

\begin{abstract}
The aim of this study was to examine the sero-prevalence and frequency of red blood cell (RBC) alloantibodies (RAAbs) and to investigate the risk factors for producing RAAbs among the Han and Uyghurs in Xinjiang. The RBC antibody screening test and identification were conducted for 45,163 Han and 70,633 Uyghurs admitted to the First Affiliated Hospital of Xinjiang Medical University from October 2010 to December 2014. RBC alloantibodies against $\mathrm{Rh}$ antigens were the most frequent, including anti-E (21.7\% in the Han, 21.6\% in Uyghurs) and anti-D (18.5\% in the Han, 18.2\% in Uyghurs). Notably, the sero-prevalence of anti-K and anti-Fy ${ }^{\mathrm{a}}$ was also high in Xinjiang. Transfusion and pregnancy were risk factors among both the Han and Uyghurs; furthermore, Uyghurs had a higher sero-prevalence of RBC antibodies compared to that of Han because of a higher incidence of these risk factors. We concluded that RBC alloantibodies against the Rh factor showed the highest frequency, and antibodies against Asian-related high-frequency antigens, including $\mathrm{Fy}^{\mathrm{a}}$ and low-frequency antigens, such as $\mathrm{K}$ were notably high in Xinjiang.
\end{abstract}

Keywords: RBC, alloantibody, minority

\section{INTRODUCTION}

Red blood cell (RBC) alloantibodies (RAAbs) is an important issue regarding blood transfusion, because RAAbs against high-frequency antigen, multiple antibodies, and additional unexpected antibodies can challenge the efficacy and safety of blood transfusion ${ }^{[1]}$. Factors that can induce the occurrence of unexpected antibodies include age, history of pregnancy, history of blood transfusion, treatment, immune status, and especially RBC density among people of different ethnical groups $^{[2-4]}$. For example, anti-Fy and anti-D are common among Caucasians, but their corresponding antigens among Asians have a positivity rate higher than $99 \%$.

Although large-scale studies have been conducted on the Han Chinese, much fewer studies have ob- served Uyghur individuals, a minority situated at the junction between Europe and China. DNA analyses indicate that Uyghurs are to the most part mixed Caucasian and East Asian, implying that their RAAbs immune status is also likely to show as correspondingly different from the Han Chinese ${ }^{[5]}$. Until now we believe no such research focusing on Middle Asian ethnical populations has been reported.

The First Affiliated Hospital of Xinjiang Medical University conducts tests for antibody identification and transfusion blood cross-matching for patients with RBC alloantibody diseases, and samples are obtained from all hospitals in the Xinjiang region. By statistically analyzing the results from the tests conducted between Oct. 2010 and Dec. 2014, this study aimed to observe the sero-prevalence of RAAbs among Uyghurs and Han in Xinjiang, in order to subsequently improve the

*Correspondence to: Xiaochuan Song, Department of Transfusion Medicine, the First Affiliated Hospital of Xinjiang Medical University, No.137 Liyushan South Road, Urumqi 830011, China. Tel: +86-13669963592; E-mail: sxc607220@163.com.

There are no conflicts of interest. 
efficacy and safety of blood transfusion.

\section{MATERIALS AND METHODS}

\section{Subjects}

Overall, 45,163 Han (23,715 males, 52.5\%), and 70,633 Uyghurs (40,160 males, 56.9\%) participants were admitted to the First Affiliated Hospital of Xinjiang Medical University from October 2010 to December 2014. All specimen were screened for RBC unexpected antibodies, while antibody identification was carried out if the test was positive. Medical records involved transfusion history and pregnancy. The other procedures such as phenotyping, sample reception, report documentation, and report writing were all based on regulations and standard procedures as specified by the First Affiliated Hospital of Xinjiang Medical University. The study protocol was approved by the Human Research Ethics Committees of the hospital.

\section{Antibody screening and identification}

The panels and screen cells used to screen and identify RBC alloantibodies, and Rh, MNS, K, Duffy, Kidd, Kell, Lewis, Pl, Xg, and Lutheran, as well as relatively high frequency antigens such as Dia and Mur were in panel kit (Immucor Inc., USA). Detection methods included conventional tube techniques at room temperature and the gel column test (Immucor Inc., USA).

\section{Statistical analysis}

A chi-square and Fisher exact tests were used to evaluate comparisons between Uyghurs and Han Chinese. Odds ratios (ORs) and $95 \%$ confidence intervals (95\%CI) were used to calculate the risk of producing RAAbs. To investigate transfusion and pregnancy as risk factors to stimulate RAAbs, subjects without RAAbs were defined as control and subjects never exposure to transfusion and pregnancy were defined as reference. Comparison results with a $2-$ sided $P<$ 0.05 were considered statistically significant. All the statistical analyses were conducted using SPSS version 19.0 (SPSS Inc., Chicago, IL, USA).

\section{RESULTS}

\section{Baseline of subjects}

In the Han population, 92 patients $(0.2 \%)$ were positive for RAAbs. In the Uyghur population, 384 patients $(0.54 \%)$ were positive for RAAbs.

Regarding transfusion history, 5,601 Han men (23.6\% of the Han men) and 12,074 Uyghur men (30.1\% of the Uyghur men) had a record of receiving transfusions.

Among 21,448 Han women, 3,515 (16.4\%) received transfusions, 1,197 (5.6\% of the Han women) experienced pregnancy, and 875 (4.1\% of the Han women) received a transfusion during pregnancy. Among 30,473 Uyghur women, 4,637(15.2\% of the Uyghur women) received transfusions, 3,140 (10.3\% of the Uyghur women) experienced pregnancy, and 2,239 ( $7.3 \%$ of the Uyghur women) received a transfusion during pregnancy. See Table 1 for further details.

Table 1 Baseline characteristics of subjects [(n)\%]

\begin{tabular}{lcccc}
\hline Characteristics & $\begin{array}{c}\text { Han } \\
(n=45,163)\end{array}$ & $\begin{array}{c}\text { Uyghurs } \\
(n=70,633)\end{array}$ & $\begin{array}{c}\text { Total } \\
(n=115,796)\end{array}$ & $P$ \\
\hline $\begin{array}{l}\text { Sex-male } \\
\text { RAAbs-positive }\end{array}$ & $92(0.2)$ & $384(0.5)$ & $476(0.4)$ & $<0.001$ \\
$\begin{array}{l}\text { Male } \\
\quad \text { Transfusion }\end{array}$ & $5,601(23.6)$ & $12,074(30.1)$ & $17,675(27.9)$ & \\
history & & & & \\
$\quad$ No exposure & $18,114(76.4)$ & $28,086(69.9)$ & $45,660(72.1)$ & \\
Female & & & & $<0.001$ \\
$\begin{array}{l}\text { Transfsuion only } \\
\text { Pregnacy only }\end{array}$ & $3,515(16.4)$ & $4,637(15.2)$ & $8,152(15.5)$ & \\
$\begin{array}{l}\text { Transfusion with } \\
\text { pregnacy }\end{array}$ & $875(4.1)$ & $2,239(7.3)$ & $3,114(5.9)$ & \\
$\quad$ No exposure & $15,861(74.0)$ & $20,457(67.1)$ & $36,318(69.2)$ & \\
\hline
\end{tabular}

\section{Frequencies of RAAbs}

Among the 476 subjects (92 Han, 384 Uyghurs) with a first-time diagnosis of specific RAAbs, the most prevalent RAAb identified was anti-E (20 Han patients, 83 Uyghurs), followed closely by anti-D (17 Han patients, 70 Uyghurs) for both populations (Table 2). Anti-E was the most prevalent form of RAAbs, with 103 cases in the anti-E only [20 cases (21.7\%) among the Han and 83 cases (21.6\%) among Uyghurs] and anti-c, E [ 3 cases $(3.3 \%)$ among the Han and 11 cases (2.9\%) among Uyghurs], followed by anti-D with 87 cases in the anti-D only [17 cases (18.5\%) among the Han and 70 cases (18.2\%) among Uyghurs], 20 cases of anti-C, D [9 cases (9.8\%) among the Han and 11 cases $(2.9 \%)$ among Uyghurs]. Notably, 7 cases with anti-K [1 Han (1.1\%) and 7 Uyghurs (1.6\%)] and 15 cases with anti-Fy ${ }^{\mathrm{a}}$ [3 Han $(3.3 \%)$ and 12 Uyghurs $(3.1 \%)$ ] were identified in our study.

\section{Risk factors for RAAbs production among the Han patients and Uyghurs}

Transfusion was a significant risk factor for the production of RAAbs in Han men (OR: 38.64, 95\%CI: 9.14-163.45). Transfusion and pregnancy were significant risk factors for the production of RAAbs in Han women (Transfusions OR: 38.0, 95\%CI: 13.49107.01; Pregnancy OR: 55.54, 95\%CI: 18.72-164.80); Han women who received a transfusion during preg- 
Table 2 Frequencies of RAAbs among the Han

\begin{tabular}{lcc}
\multicolumn{2}{c}{ patients and Uyghurs } & {$[(n) \%]$} \\
\hline Antibody specificity & $\begin{array}{c}\text { Han } \\
(n=92)\end{array}$ & $\begin{array}{c}\text { Uyghurs } \\
(n=384)\end{array}$ \\
\hline Single RAAbs & \\
Anti-D & $17(18.5)$ & $70(18.2)$ \\
Anti-C & $5(5.4)$ & $19(4.9)$ \\
Anti-c & $2(2.2)$ & $11(2.9)$ \\
\hline Anti-E & $20(21.7)$ & $83(21.6)$ \\
\hline Anti-e & $2(2.2)$ & $6(1.6)$ \\
Anti-M & $3(3.3)$ & $12(3.1)$ \\
Anti-S & $2(2.2)$ & $5(1.3)$ \\
\hline Anti-Le & $6(6.5)$ & $26(6.8)$ \\
Anti-Le & $21(5.5)$ \\
\hline Anti-P1 & $5(5.4)$ & $15(3.9)$ \\
\hline Anti-Jk & $3(3.3)$ & $21(5.5)$ \\
\hline Anti-Jk & $16(4.2)$ \\
Anti-K & $5(5.4)$ & $6(1.6)$ \\
\hline Anti-Fy & $3(3.3)$ & $12(3.1)$ \\
\hline Anti-Fy & $1(1.1)$ & $16(4.2)$ \\
\hline Multiple RAAbs & $3(3.3)$ & \\
\hline Anti-cE & $2(2.2)$ & $11(2.9)$ \\
\hline Anti-Ce & $3(3.3)$ & $11(2.9)$ \\
\hline Anti-CD & $2(2.2)$ & $11(2.9)$ \\
\hline Autoantibodies & $9(9.8)$ & $14(3.6)$ \\
\hline
\end{tabular}

nancy also tended to produce RAAbs (OR: 49.24, 95\% CI: 15.71-154.34) (Table 3).

Table 3 Transfusion and pregnancy as risk factors for the production of RAAbs among the Han patients

\begin{tabular}{|c|c|c|c|c|c|}
\hline Risk factors & Case & Case+Control & OR & $95 \% \mathrm{CI}$ & $P$ \\
\hline \multicolumn{6}{|l|}{ Male } \\
\hline Transfusion & 24 & 5,601 & 38.64 & $9.14-163.45$ & $<0.001$ \\
\hline No exposure & 2 & 18,114 & Reference & Reference & \\
\hline \multicolumn{6}{|l|}{ Female } \\
\hline Transfsuion only & 34 & 3,515 & 38.00 & $13.49-107.01$ & $<0.001$ \\
\hline Pregnacy only & 17 & 1,197 & 55.54 & $18.72-164.80$ & $<0.001$ \\
\hline $\begin{array}{l}\text { Transfusion with } \\
\text { pregnacy }\end{array}$ & 11 & 875 & 49.24 & $15.71-154.34$ & $<0.001$ \\
\hline No exposure & 4 & 15,861 & Reference & Reference & \\
\hline
\end{tabular}

Transfusion was a significant risk factor for the production of RAAbs in Uyghur men (OR: 73.48, 95\%CI: 30.18-178.90). Transfusion and pregnancy were significant risk factors for the production of RAAbs in Uyghur women (Transfusions OR: 25.49, 95\%CI: 12.57-51.69; Pregnancy OR: 69.49, 95\%CI: 35.13-137.48); Uyghur women who received a transfusion during pregnancy also tended to produce RAAbs (OR: 62.94, 95\%CI: 31.33-126.47) (Table 4).

Table 4 Transfusion and pregnancy as risk factors for the production of RAAbs among Uyghurs

\begin{tabular}{lrrrrr}
\hline Risk factors & \multicolumn{7}{c}{ Case Case+Control } & OR & $95 \%$ CI & $P$ \\
\hline Male & & & & & \\
Transfusion & 160 & 12,074 & 73.48 & $\begin{array}{c}30.18- \\
178.90\end{array}$ & $<0.001$ \\
No exposure & 5 & 28,086 & Reference & Reference & \\
$\begin{array}{l}\text { Female } \\
\text { Transfsuion }\end{array}$ & 52 & 4,637 & 25.49 & $12.57-51.69<0.001$ \\
$\begin{array}{l}\text { only } \\
\text { Pregnacy only }\end{array}$ & 96 & 3,140 & 69.49 & $35.13-137.48<0.001$ \\
$\begin{array}{l}\text { Transfusion } \\
\text { with pregnacy }\end{array}$ & 62 & 2,239 & 62.94 & $31.33-126.47<0.001$ \\
$\quad$ No exposure & 9 & 20,457 & Reference & Reference & \\
\hline
\end{tabular}

\section{Risks of transfusion and pregnancy to im- mune RAAbs among Uyghurs and Han}

The sero-prevalence of RAAbs with transfusion was $1.3 \%$ in Uyghur men and $0.4 \%$ in Han men. Transfusion was an obvious risk factor for Uyghur and Han men for the production of RAAbs, and Uyghur men had a higher risk than Han men (OR: 3.07, 95\%CI: 2.00-4.07).

Uyghur women tended to produce RAAbs by both transfusion and pregnancy more so than Han women. The pregnancy-related sero-prevalence of RAAbs in Uyghur women was $3.1 \%$, in contrast to $1.4 \%$ in Han women; further, pregnancy with transfusion-related sero-prevalence of RAAbs in Uyghur women was $2.8 \%$, in contrast to $1.3 \%$ in Han women.

Table 5 The risk factors of transfusion and pregnancy for RAAbs production in the Uyghurs and Han patients

\begin{tabular}{|c|c|c|c|c|c|c|c|c|c|}
\hline \multirow{2}{*}{ Risk factors } & \multicolumn{3}{|c|}{ Uygur } & \multicolumn{3}{|c|}{ Han } & \multirow{2}{*}{ OR } & \multirow{2}{*}{$95 \% \mathrm{CI}$} & \multirow{2}{*}{$P$} \\
\hline & Case & Case+Control & Positive rate, $\%$ & Case & Case+Control & Positive rate, $\%$ & & & \\
\hline Male & 165 & 40,160 & & 26 & 23,715 & & & & \\
\hline Transfusion & 160 & 12,074 & 1.30 & 24 & 5,601 & 0.40 & 3.07 & $2.00-4.70$ & $<0.001$ \\
\hline No exposure & 5 & 28,086 & 0.02 & 2 & 18,114 & 0.01 & 1.61 & $0.31-8.31$ & 0.437 \\
\hline Female & 219 & 30,473 & & 66 & 21,448 & & & & \\
\hline Transfsuion only & 52 & 4,637 & 1.10 & 34 & 3,515 & 0.97 & 1.16 & $0.75-1.78$ & 0.290 \\
\hline Pregnacy only & 96 & 3,140 & 3.10 & 17 & 1,197 & 1.40 & 2.11 & $1.27-3.53$ & 0.001 \\
\hline Transfusion with pregnacy & 62 & 2,239 & 2.80 & 11 & 875 & 1.30 & 2.17 & $1.15-4.10$ & 0.007 \\
\hline No exposure & 9 & 20,457 & 0.04 & 4 & 15,861 & 0.03 & 1.74 & $0.54-5.66$ & 0.258 \\
\hline
\end{tabular}

\section{DISCUSSION}

This is a first report of patients testing positive for unexpected antibodies among Han and Uyghur patients in Xinjiang during 2010-2014. The number of subjects enrolled in our study was 115,796 patients, including 45,163 Han and 70,633 Uyghurs. The study suggested that transfusion and pregnancy are risk factors that lead to the production of RAAbs included both relatively common types and very rare types like 
anti-Fy ${ }^{\mathrm{a}}$ and anti-K, which Han from other regions generally do not have.

In this study, the antibodies against Rh, Kidd, Lewis and MNs systems and the RAAbs against the $\mathrm{Rh}$ factor were the most frequently reported RAAbs. Notably, the anti-D was the second highest in seroprevalence for both Han (18.5\%) and Uyghurs (18.2\%) from Xinjiang; this frequency is high compared to the $3.1 \%$ for Han living in Beijing ${ }^{[5]}$.

Furthermore, our report also demonstrated the RAAbs anti-K (1.1\% Han, 1.6\% Uyghurs) and antiFy ${ }^{\mathrm{a}}(3.1 \%$ Han, $3.3 \%$ Uyghurs) had a higher value in our study as compared to $0.19 \%$ and $0.14 \%$, respectively, for Han people living in Beijing ${ }^{[6]}$. Further analysis is required to identify specific human erythrocytic antigens and their related frequency for Han and Uyghurs so that a local clinical strategies for transfusion can be developed.

Our study has confirmed transfusion as a risk factor for the production of RAAbs in both Han and Uyghur men and women from Xinjiang. Pregnancy was a significant additional risk factor for women ${ }^{[7,8]}$; however, both Han and Uyghur women who received transfusions during pregnancy did not experience the expected increase in incidence; this may be because the pregnant women who needed transfusions may have been in worse clinical condition. The Uyghurs have a greater tendency to produce RAAbs following transfusion or pregnancy than the Han people. Further studies to analyze the immune-related genes should be conducted; this could include human leukocyte class II typing or frequencies of various blood group antigens ${ }^{[9]}$. Our study was limited to observe the frequencies of RAAbs in Xinjiang among the Han and Uyghurs, but we did not collect evidence for their immune status, such as immune factors like human erythrocytic antigens and complicating factors like HLA class II .

RAAbs against the Rh factor, especially anti-E and
anti-D were the most prevalent RAAbs, with notable results for anti-K and anti-Fy ${ }^{\mathrm{a}}$. Transfusion for both men and women and pregnancy for women were the significant risk factors that produced RAAbs in Xinjiang among Han and Uyghurs.

\section{References}

[1] Sood R, Makroo RN, Riana V, et al. Detection of alloimmunization to ensure safer transfusion practice. Asian J Transfus Sci, 2013,7(2):135-9.

[2] Zalpuri S, Schonewille H, Middelburg R, et al. Effect of storage of red blood cells on alloimmunization. Transfusion, 2013,53(11):2795-800.

[3] Schonewille H, Doxiadis, II, Levering WH, et al. HLADRB1 associations in individuals with single and multiple clinically relevant red blood cell antibodies. Transfusion, 2014,54(8):1971-80.

[4] Chow MP, Hu HY, Lyou JY, et al. Red cells, HLA and platelet antibody formation in patients with multiple transfusions. Acta Haematol, 1994,92(2):57-60.

[5] Bai XH, Lan JC, Gong XY, et al. Study on RHCE genotyping of $\mathrm{Rh}$ blood group in Uygur nationality of Xinjiang in China. J Exp Hematol(in Chinese), 2010, 18(5):1335-7.

[6] Lin YS, Chang JS, Qiu Y, et al. Incidence of unexpected red blood cell antibodies in the north of China. Asia-Pacific Journal of Blood Types and Genes, 2017,1(1):17-24.

[7] Verduin EP, Brand A, Middelburg MA, et al. Female sex of older patients is an independent risk factor forred blood cell alloimmunization after transfusion. Transfusion, 2015, 55: 1478-85.

[8] Verduin EP, Brand A, Schonewille H. Is female sex a risk factor for red blood cell alloimmunizationafter transfusion? A systematic review. Transfus Med Rev, 2012, 26(4): 342-53.

[9] LinYS, Xu ZY, Li XF, et al. Association of HLA-DRB1 and HLA-DQB1 alleles with red blood cell autoimmunization in the Chinese population. Asia-Pacific Journal of Blood Types and Genes, 2017,1(2):31-4.

(Received 03 June 2017, Revised 24 August 2017, Accepted 04 September 2017) 